\title{
SCAN-TO-BIM METHODOLOGY ADAPTED FOR DIFFERENT APPLICATION
}

\author{
V. Badenko ${ }^{1,}$ *, A. Fedotov ${ }^{1}$, D. Zotov ${ }^{1}$, S. Lytkin ${ }^{1}$, D. Volgin ${ }^{1}$, R. D. Garg ${ }^{2}$, Liu Min ${ }^{3}$ \\ ${ }^{1}$ Peter the Great St. Petersburg Polytechnic University, Civil Engineering Institute, 195251 Polytechnicheskaya 29, St. Petersburg, \\ Russian Federation, - (badenko_vl, afedotov, zotov_dk)@spbstu.ru, (lytkin_sa, volgin.dyu)@edu.spbstu.ru \\ ${ }^{2}$ Indian Institute of Technology Roorkee, Civil Engineering Department, Roorkee-247667, India rdgarg@ gmail.com \\ ${ }^{3}$ East China Normal University, School of Geographic Sciences, 500 Dongchuan Rd, Minhang Distract, Shanghai, 200241, China, \\ mliu@geo.ecnu.edu.cn
}

Commission V, WG V/7

KEY WORDS: 3D laser scanning, scan-to-BIM technique, as-build BIM models, historic buildings, existing industrial buildings

\begin{abstract}
:
In this paper we proposed a methodology that describes the major steps of a scan-to-BIM process. The methodology includes six steps: (1) classification of considered elements, (2) definition of required level of detail (GI), (3) scan data acquisition, (4) point cloud registration and segmentation, (5) as-built BIM creation and (6) analysis. The examples of the application of the proposed methodology are demonstrated by creation of as-built BIM models for existing industrial sites and historic buildings. As the results of these case studies have shown, the proposed methodology can be used for as-built BIMs without any prior information.
\end{abstract}

\section{INTRODUCTION}

Building information modelling (BIM) became very popular technology in the civil engineering and asset management industries in recent decades (Ghaffarianhoseini et al., 2017). BIM helps civil engineering specialists and asset managers to support all information/knowledge about the assets throughout its lifecycle, from beginning to demolition, which allows talking about the emergence of digital assets (Volk et al., 2014; Roberts et al., 2018). Accurate graphic and adequate attribute information in BIM-models are the key factors to successful BIM implementation especially in operation and maintenance phase of asset lifecycle (Kivits and Furneaux, 2013). Most of the existing assets do not have any BIM-model, which for existing building is known as as-built BIM-models (Tang et al., 2010). To resolve such a problem of a digital model absence, the laser scanning technologies have been widely adopted in the as-built BIM creation industry (Pärn et al., 2017; Badenko et al., 2018a, Badenko et al., 2018b). Thus, creation of the as-built BIM-models can be based on laser scanning data used to obtain accurate building parameters, primarily geometric, and this process is called as the scan-to-BIM process (Bosché et al., 2015).

The main advantages of the laser scanning technologies are characterized by high geometric accuracy (up to millimetres) and very fast measurements (up to one million points per second) in comparison to traditional optical and satellite geodetic methods. The output from laser scanning is similar to the data obtained from photogrammetric surveys and includes high resolution images, 3D point clouds with triangulated surface models and textured surface models. All type of laser scanning technologies (terrestrial, mobile and airborne) provides an accurate, efficient and easy to use solution for acquiring 3D data required for as-built BIM-models. Thereby laser scanning technologies have great prospects for use in the creation of as-built BIM-models. However, the relatively high cost of the laser scanning technologies for as-built BIM application should be considered. Mentioned perspectives are especially clearly recognized when analyzing widely represented in the literature (Dore and Murphy, 2017; Pocobelli et al., 2018; Fateeva et al., 2018) results of the creation of the BIM-models for an historic buildings (HBIM). Also, at present, the importance of as-built BIM-models for creating digital twins or digital assets for existing industrial plants is increasing due to the downward trend in the cost of laser scanning technology (Whyte et al., 2016; Son and Kim, 2017; Nguyen and Choi, 2018; Roberts et al., 2018).

Various studies have been conducted on the as-built BIMmodelling of industrial objects. For example, an improved technique for the on-site dimensional inspection of the piping systems of an industrial plant have been proposed (Nguyen and Choi, 2018). However, despite the high recognition rate some objects remained unrecognized due to poor scan station planning.

The related works review showed that the research is mainly focused on specific technology stages of as-built BIM technology, for example the pipe recognition, but the whole BIM-modelling process is not clearly described because of missed specification of important steps.

Therefore, the objective of our research is to propose an adaptive method for modelling existing facilities and analysing obtained models, which can be easily repeated. The method can bridge some gaps in existing technologies. The study would outline opportunities and challenges for the use of BIM in both industrial and heritage practices. Also scan-to-BIM methodology adapted for different application including creation of as-built BIM-models for existing industrial sites and historical buildings is demonstrated.

\section{METHODS}

Figure 1 shows proposed methodology including six steps:

\footnotetext{
* Corresponding author
} 
(1) classification of elements that will be considered when creating an as-built BIM-model for an existing building/asset;

(2) definition of required level of details for elements considered including level of geometry accuracy and attributes information fullness (GI);

(3) definition of scanning parameters including type of scanner, optimization of the number of scan positions for scan-to-BIM procedures, and acquisition of laser scanning data;

(4) these scans acquired (several specific point clouds) must be combined and registered in the same coordinate system to obtain the complete united point cloud that is a point model of a real building/asset;

(5) processing of this laser scanning point cloud, with information about the 3D coordinates of the points, the intensity of the reflected laser beams and RGB colour, for the generation of an as-built BIM-models using number of specific software; (6) analysis and usage of the BIM-model obtained.

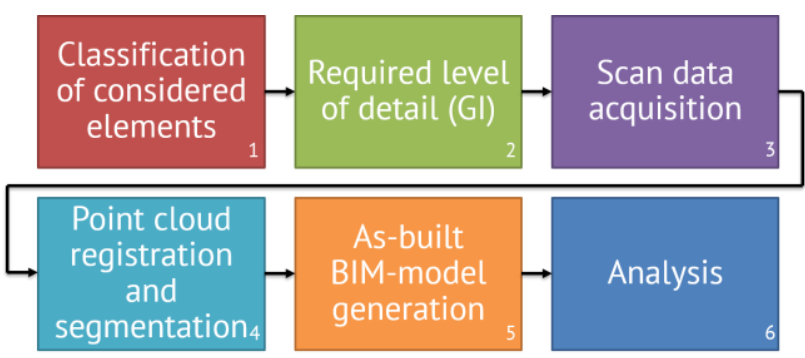

Figure 1. Six steps of the proposed methodology

Some comments for each step of the proposed methodology are following below.

The result of the first step is a description of the elements of building in a standardized form. These considered elements of existing building are elements that should be included in the asbuilt BIM-model on the fifth step. A list of types of such element should be identified using a certain building element classification system. There are numbers of such classification systems, for example: MasterFormat, UniFormat, Uniclass, etc. (Volk et al., 2014; Antón et al., 2018; Wang et al., 2019). We decide to use OmniClass classification system because it is incorporated inside a number of 3D BIM authoring software e.g. Revit (Saleeb et al., 2018). Figure 2 shows example of OmniClass classification (OmniClass, 2019).

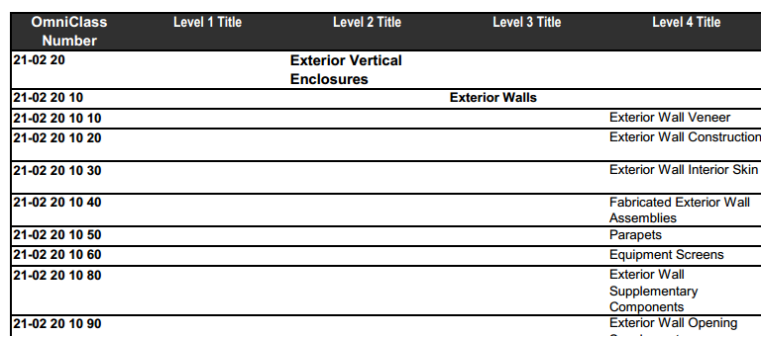

Figure 2. Example of OmniClass classification

OmniClass is designed to provide a standardized basis for classifying information created and used by the North American architectural, engineering and construction (AEC) industry, throughout assets lifecycle and encompassing all of the different types of asset. OmniClass is intended to be the means for organizing, sorting, and retrieving information and deriving relational computer applications. OmniClass consists of 15 hierarchical tables, based on ISO 12006-2 (Organisation of Information about building Works - Framework for Classification) each of which represents a different facet of construction information. The depth of levels of the tables varies from two to eight levels of hierarchy and each table can be used independently to classify a particular type of building information (Leite and Akinci, 2011).

In the second step, the specific level of model details (LOD) is determined. The concept of LOD is widely discussed in publications and is used in applications (Volk et al., 2014; Anil et al., 2013; Badenko et al., 2018c; Brumana et al., 2018; Wang et al., 2019). The traditional concept of the LOD applied to the BIM management in the case of new construction is based on a linear building lifecycle process progressively enriching the BIM-model across the different lifecycle stage. It should be noted that there is even a different accent in the letter " $\mathrm{D}$ " in the abbreviation LOD, as the level of detail and as the level of development (Brumana et al., 2018). LOD100 represents a conceptual model, LOD200 represents a model with approximate geometry, LOD300 represents a three-dimensional model in the executive design phase with precise geometry, LOD400 represents the model implemented for the construction (fabrication) phase and LOD500 represents the as-built updating after the construction phase. Consequently, all elements in scan-to-BIM process should be classified as LOD 500 (as-built BIM-model). As it can be seen, additional classification is needed. We have proposed a useful specification on the base of two important parameters of the elements considered: geometry accuracy and information fullness of elements attributes (Table 1). Here we must point out, that the extended notion of attributes is used, which includes not only numerical values, but also images, documents, etc.

\begin{tabular}{|c|c|c|c|c|}
\hline \multicolumn{2}{|c|}{} & \multicolumn{3}{c|}{ Information fullness, I } \\
\cline { 3 - 5 } \multicolumn{2}{|c|}{} & 1 & 2 & 3 \\
\hline \multirow{2}{*}{$\begin{array}{c}\text { Geometry } \\
\text { accuracy, } \\
\text { G }\end{array}$} & 1 & GI 11 & GI 12 & GI 13 \\
\cline { 2 - 5 } & 2 & GI 21 & GI 22 & GI 23 \\
\cline { 2 - 5 } & 3 & GI 31 & GI 32 & GI 33 \\
\hline
\end{tabular}

Table 1. Possible combinations of information fullness and geometry accuracy in scan-to BIM process

The meaning of the presented gradation for the geometry accuracy $(\mathrm{G})$ of the elements is following:

1 - a schematic representation of the elements to display the overall dimensions of the elements, with taking into account only its shape modeled by a set of simple surfaces;

2 - middle precision geometry with accuracy for shape till 50 $\mathrm{mm}$, all elements are solid-state;

3 - precise geometry of solid-state elements with an accuracy of up to $5 \mathrm{~mm}$, which allows modeling of the complex architectural shapes.

The meaning of the presented gradation for the information fullness (I) of the elements considered is following:

1 - minimum of attribute information, including RGB color;

2 - attribute information about the materials and the structure of the elements are adequate for various numerical simulation, including thermal and finite elements strength calculations;

3 - all information available on the object are integrated into the model.

Possible combinations of $\mathrm{G} \& \mathrm{I}$ may be corresponding to following applications:

GI 11 - large-scale visualization of the external forms of historic buildings is required;

GI $12-$ a preliminary design scheme is required for a preliminary static strength analysis;

GI 13 - the creation of a database of the object without exact binding to the geometry is required;

GI 21 - insolation standards verification for building; 
GI 22 - detailed finite element analysis of the bearing capacity of building structures;

GI 23 -feasibility study of investment projects;

GI 31 - checking location and passage of construction equipment near the building for possible collisions;

GI 32 - engineering network design;

GI 33 - preparation of the project of restoration/reconstruction of the cultural heritage object.

The result of third step is a set of laser scanning point clouds. These clouds are obtained with required scanning parameters including selection of appropriate equipment and a plan of scanning with specific quality and resolution.

The result of preprocessing of the point cloud in the fourth stage is a registered and segmented united point cloud, which have been converted to the required coordinate system and can be processed in the BIM software.

In the fifth and sixth stages of the methodology, a large number of options arise that depend on specific applications. In section 3 (Results and Discussions) some specific examples of applications are presented, and the content of these steps will became more clear. Here we confine ourselves to few general comments.

While processing point clouds with complex geometry, like for cultural heritage, it is necessary (for some objects) to create a spherical mesh. It is convenient to build such mesh in the 3DReshaper software and then export the mesh in Revit for creation specific families. After creation of as-built BIM-model within Revit software, it is possible to analyse it in Autodesk Robot Structural Analysis.

On the other hand, when solving a different type of problem, for example, when creating a BIM-model at an industrial site, where such elements are metal structures, reinforced concrete columns and beams, a different approach is used. In this case, one can use the Faro Focus 3D phase terrestrial laser scanner and other software for processing laser scanning data, such as Leica Cyclone. After as-built BIM-model creation it is also possible to analyse model in Navisworks software.

\section{RESULTS AND DISCUSSIONS}

Two case studies are presented for processing a laser scanning point cloud for a cultural heritage building and an existing industrial site. Both case studies have a great practical value.

\subsection{Case study 1. Mansion of Spiridonov N.V.}

The efficiency of our scan-to-BIM framework is confirmed by the example of its application for historical building. According to local authority regulations this object of research is included in the list of cultural heritage buildings in St. Petersburg. The objective of this case study is creation as-built BIM-model including a comprehensive survey, collecting a database of the building, updating the current paper documentation and creating the basic database for the reconstruction project design. The specific implementation scheme of the proposed methodology for this case study is presented in the figure 3 .

The priority elements were exterior walls, floor construction, roof construction, exterior windows, exterior doors and grilles. In accordance with our classification of possible combinations of information completeness and accuracy of geometry in the scan-to-BIM process (Table 1), we chose the combination GI 33. This index is determined by the future BIM application (the technical and economic rationale of investment projects for historical building). Required accuracy of measurement for each element was adopted $5 \mathrm{~mm}$ for size, shape, and location. The phase terrestrial laser scanner Riegl VZ-400, which allows to effectively scanning at a distance of 50-70 meters with an accuracy of determining distances up to $1 \mathrm{~mm}$ was used to perform the filed works. Indoor \& outdoor scanning was performed from 265 stations/places with $1 / 4$ resolution and $3 x$ quality. Figure 4 shows the historical building under examination.

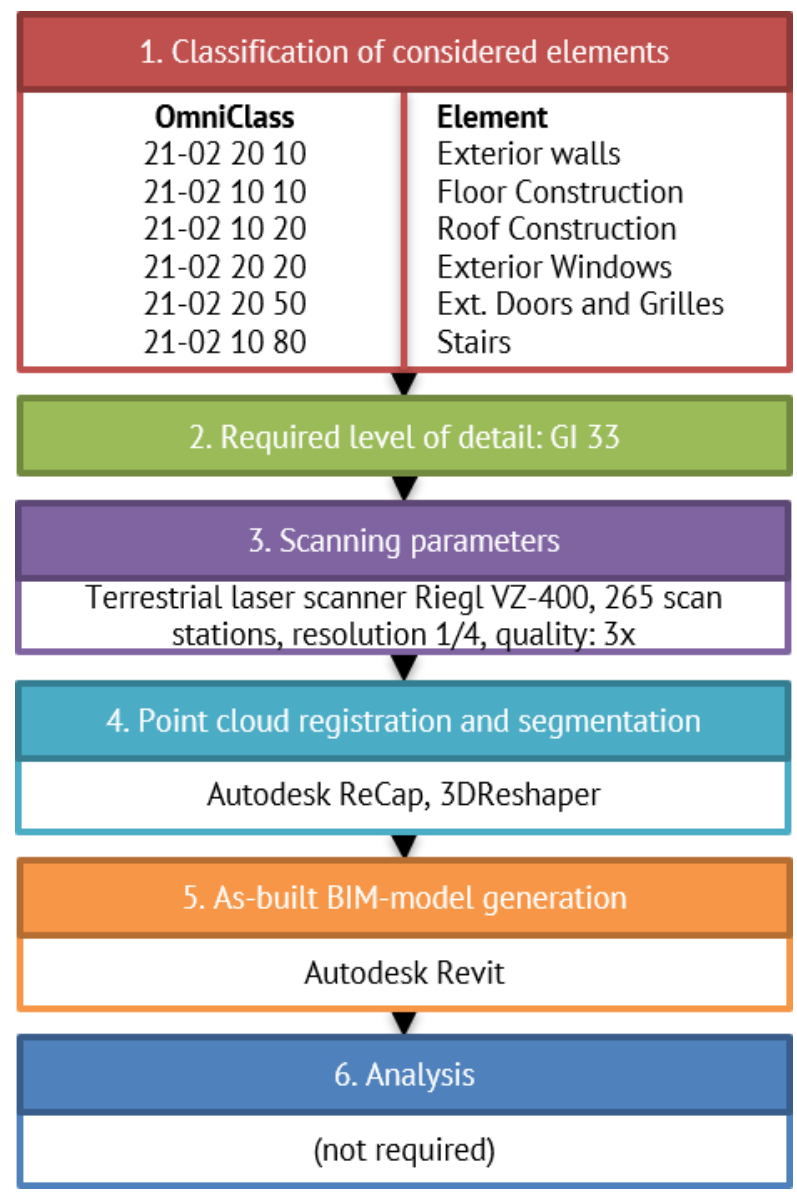

Figure 3. Scheme of the proposed methodology for historical heritage case study

Raw clouds of laser scanning points were obtained as a result of laser scanning. These point clouds were processed in Autodesk ReCap software and registered into a unite point cloud (Figure 5). Further, this cloud was manually segmented, as a result of which some unnecessary points were removed and total number of points was reduced by $5 \%$.

After processing, point cloud was imported into Autodesk Revit software, where as-built BIM-model (Figure 6) was generated with necessary accuracy $(5 \mathrm{~mm})$ and level of detail. Relatively simple elements, such as floors and walls, were created by hand, which took a lot of time due to the large number of elements and the amount of information. Then all elements were manually classified according to OmniClass Classification System for quick information management.

The process of generation complex structures was completed by segmentation and meshes creation within 3DReshaper software. Then meshes obtained were converted into Revit families with the addition of the required information. It should be noted that working with polygonal geometry requires high computer performance. Therefore, during generation of such a large BIMmodel, some decelerations were occurred, that increased the duration of the project. 


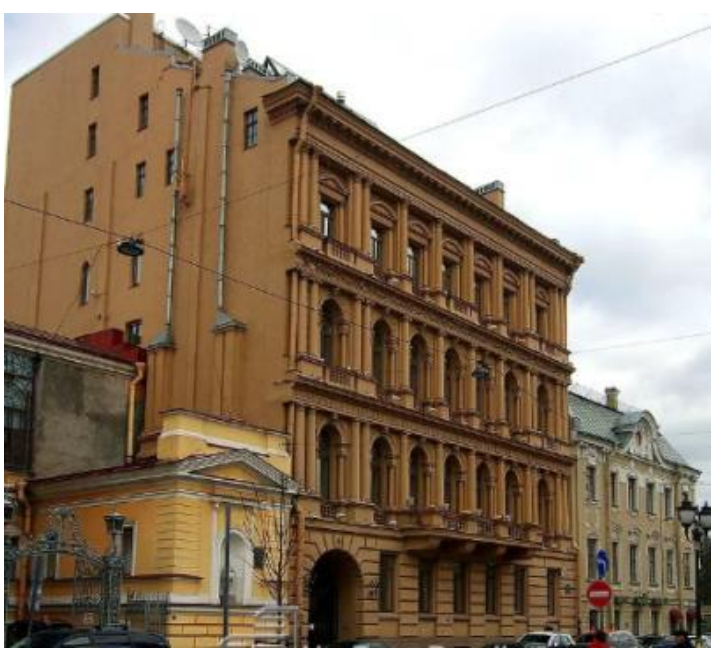

Figure 4. Historical heritage case study

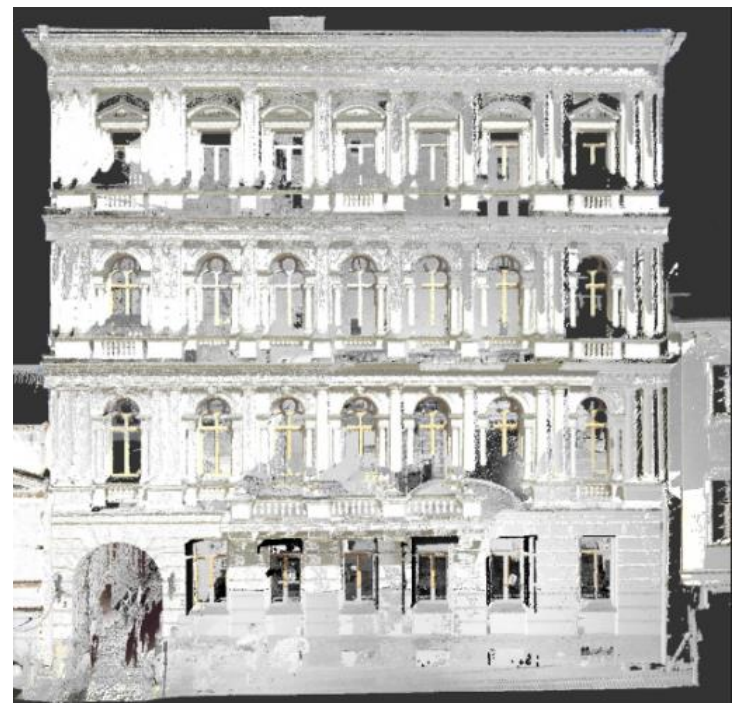

Figure 5. Processed point cloud for historical heritage case study

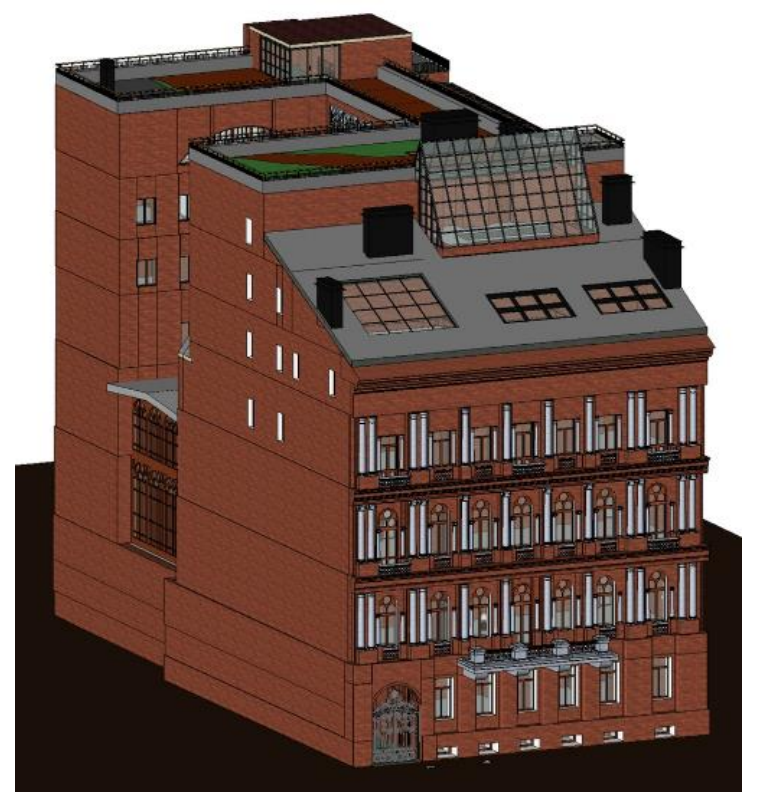

Figure 6. As-built BIM-model for historical heritage case study
In this case, it is recommended to use specialized commercial add-ons software like PointCab, PointSense, etc. for semiautomatic generation of simple elements. Also, in this case it was necessary to use NURBS (Barazzetti, 2016) geometry due to the fact that the model has different levels of floor in the rooms and vaulted ceilings. Moreover, NURBS geometry is processed faster and allows us to flexibly adjust the shape of the element, adjust its faces if necessary. Therefore, non-standard architectural elements inherent in the historical building of Saint-Petersburg, Russia were created as Revit families.

\subsection{Case study 2. SPbPU Future Factory}

he second example of application of the methodology is focused on creating an as-build BIM-model for an existing industrial site. The objective of this case study was to create as-built BIMmodel for support of decisions making during design of a reconstruction of an existing industrial site, including insolation and new industrial technology allocation (Future Factory projects). According the objective of this example, first of all we are interested in dimensions of the existing facilities, as well as the position and properties of the main existing support structures. These elements are crucial for choosing positions of elements/equipment of a new industrial technological process, relative to already existing elements. Thus, the elements of the as-build BIM-model were selected. It should be noted that the existing metal structures that serve as supporting elements were of special interest. The specific implementation scheme of the proposed methodology for this case study is presented in the figure 7.

Despite the fact that GI11 (Table 1) level should be sufficient for determine the size in accordance with the design requirements, the need for examination and analysis of metal structures imposes a restriction on the allowable error of geometric measurements and the informational completeness of elements that require analysis. Therefore, we chose the GI 22 level (Table 1) to build a relatively accurate model of metal trusses, dimensions and openings of the premises. Since it requires only indoor scanning, the relatively simple and inexpensive Leica BLK 360 laser scanner was used. This scanner allows to effectively scan at a distance of 20 meters with an accuracy of determining distances up to $8 \mathrm{~mm}$. Indoor scanning was performed from 10 stations/places with medium resolution. One useful feature of the Leica BLK 360 is that, when scanning, you can automatically register sequentially received scans using the embedded software in the Autodesk ReCap mobile app on the iPad. Figure 8 shows the resulting combined laser scanning point cloud for the existing industrial site.

Then the point cloud was exported into CloudCompare and segmented inside this software. The existing industrial site has a large number of metal structures that had to be analysed in the BIM environment. After registration and segmentation, the point cloud was imported into Leica Cyclone software for processing and digitising metal structures profiles of the structures.

As the as-built BIM software the Autodesk Revit was used. Preprocessed point cloud was imported into Revit software, where the final as-built BIM-model was generated with achieved accuracy of $50 \mathrm{~mm}$. Metal structures were exported to Robot Structural Analysis to form a finite element mesh and static calculation. Insolation analysis was performed using the add-on for Revit, Autodesk Insight, which requires specifying the exact location of the object on the earth's surface. Geolocation and orientation of the building were set using registered satellite 
images with an insignificant error for this task: within two meters for coordinates and 5 degrees for direction. For a complete simulation, the outlines of nearby buildings were constructed with the same permissible error. A subsequent analysis of the design decisions on the admissibility of the proposed new equipment/facilities positions and checking for collisions absence was performed in Navisworks (Figure 9).

According to the results of a comprehensive survey and analysis, a number of shortcomings were identified in the proposed reconstruction project. Modeling of a large-size vehicle transit showed that the design arrangement of partitions and equipment prevents the movement of cargo and construction equipment inside the premises. The control of the design marks of the erected structures showed the lack of the necessary height margin. Insolation analysis at Autodesk Insight showed that there is relatively a lot of sunlight coming into the room, but not enough for industrial use (Figure 10). It requires the placement of additional lighting equipment in order to meet the requirements of safety standards for industrial premises. Static calculation of metal trusses showed that the loads and deflections do not exceed the allowable values.

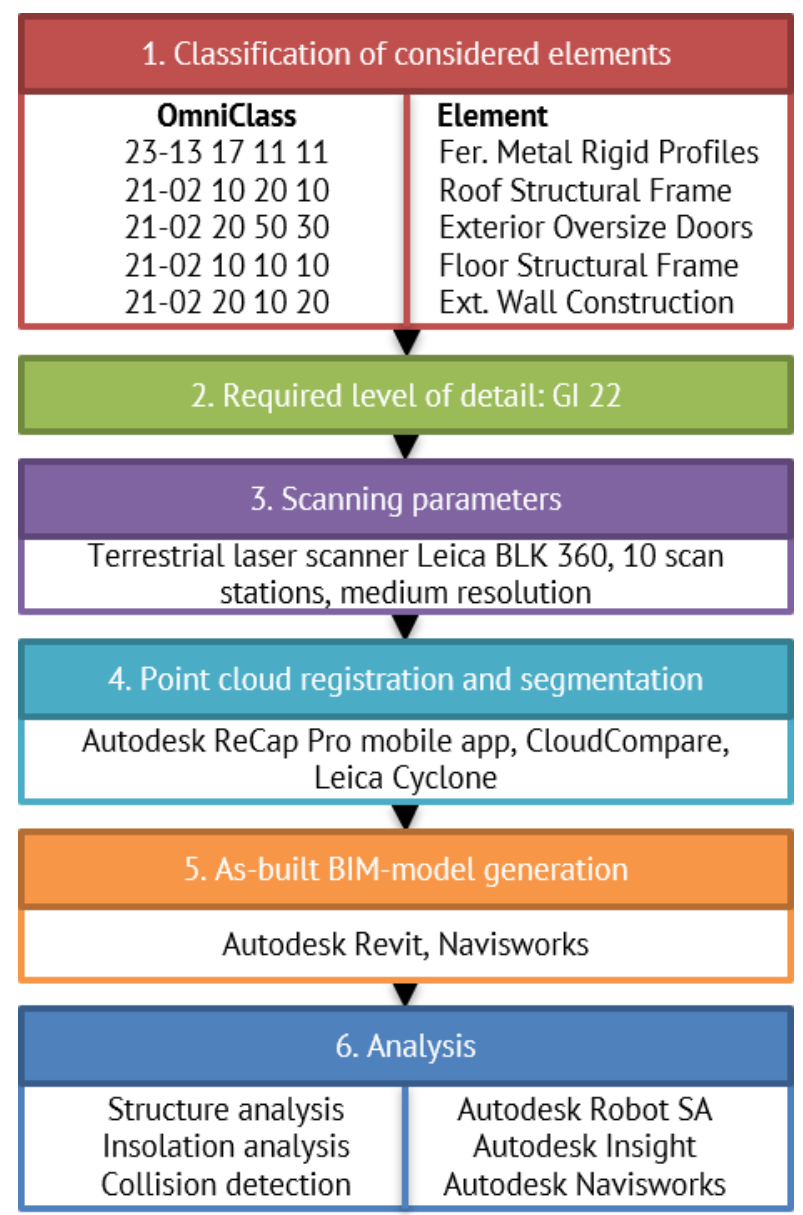

Figure 7. Scheme of the proposed methodology, which is tuned for the case study for existing industrial sites

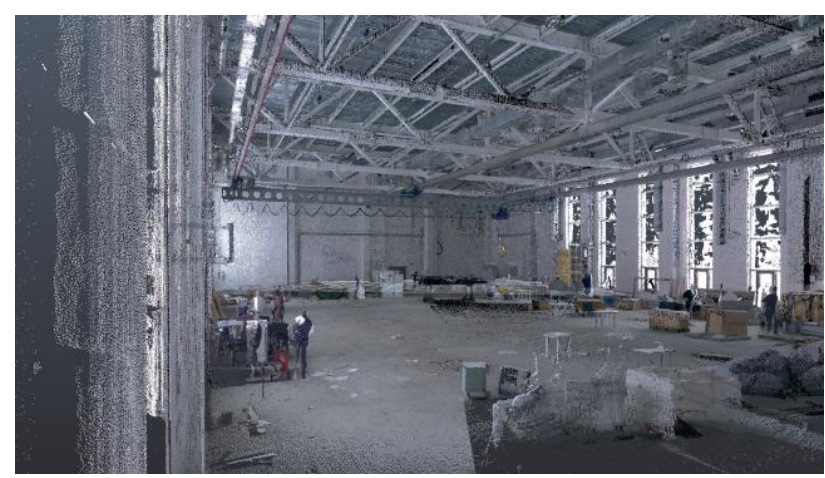

Figure 8. Point cloud for existed industrial site case study

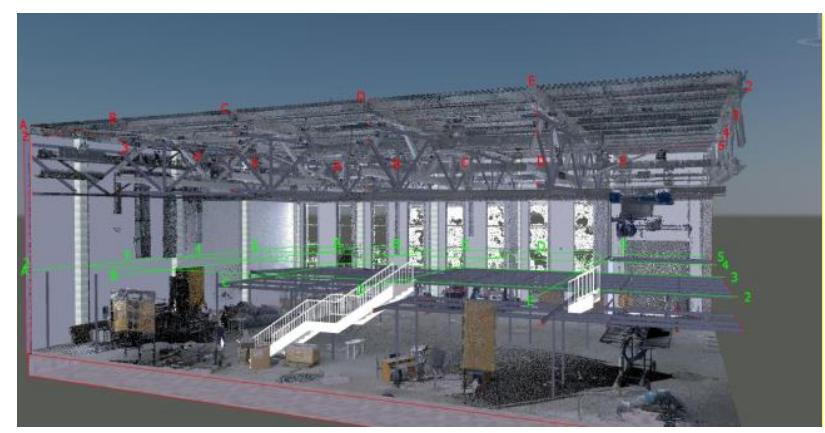

Figure 9. Navisworks assembly: as-built BIM-model of the existing industrial site and analyzed renovation project

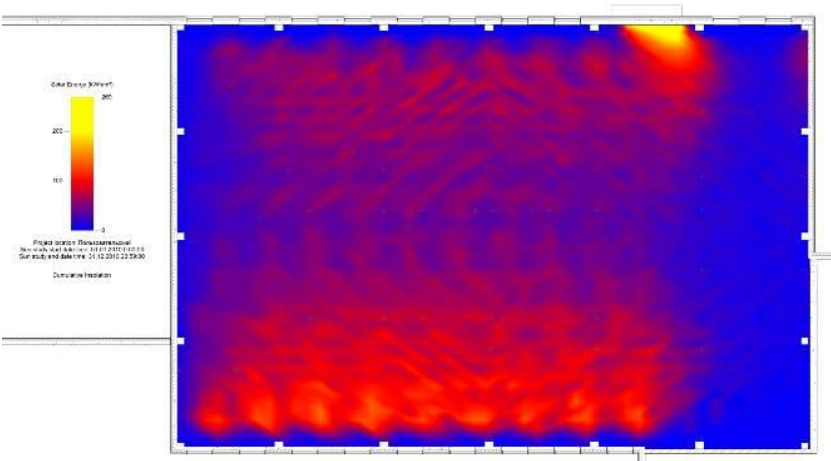

Figure 10. Cumulative insolation analysis

\section{CONCLUSIONS}

Scan-to-BIM framework adapted for different application was demonstrated. The framework proposed is easy to replicate. Useful specification system (GI index) was applied. Point cloud processing and as-built BIM generation was made according to proposed methodology with necessary accuracy and level of detail. This study demonstrated that the main difficulties for users are related to the lack of universal software for the creation of as-built BIM-models. Therefore, in the proposed framework it is necessary to carry out numerous export / import operations, which greatly affects the efficiency of projects. However, our experience has shown that proposed adaptive method for modelling existing facilities and analysing obtained BIM-models has great potential for widespread use in the AEC field.

We can say that the modelling part was complicated by the excessive density of the processed cloud and a large number of artefacts. Thus, in future works it is necessary to take into account this factor and make pre-processing of the clouds first. 
For example, we can use random and space sampling in Cloud Compare for automatically remove unnecessary points or reduction in the number of points.

During case study the data mostly have been processed manually, which was very labour-intensive, but some gaps in existing technologies have been bridged. It can be said with confidence that with an appropriate level of automation of this process, the technology will become profitable and will be widely adopted. Automation today can be enhanced by the integrated and skilful application of a variety of software and technologies. For semi-automatic generation of elements like the floor, flat ceiling and walls, some specialized add-ons are needed. Scenarios for the parameterization of complex geometry are also widely used through visual programming platforms like Dynamo and Grasshopper. With a complex survey of a number of structures of the same historical period and architectural style, it is advisable to use the appropriate library of parametric elements.

The direction of future research is the study and testing of all the above-listed technologies, the assessment of their applicability and the impact on labour costs and accuracy.

Using the example of an industrial site, we proved that as-built BIM technology allows solving a wide range of professional tasks in the shortest possible time and with maximum accuracy. We face the problem that used BIM design software doesn't have the capability to convert geometric primitives created with reverse engineering tools in Leica Cyclone into BIM objects. The need to re-model the geometry within a BIM design environment using the reverse engineering model as guidance characterizes the current interoperability problem. Justification of design decisions, control of transport passage, checking for collisions, and calculation of insolation and static finite element analysis of load-bearing structures are only part of the possible application scenarios. In future studies, we will try to expand this range of tasks, cover new areas and correct the shortcomings identified at the previous stage.

In this study, Autodesk BIM software was primarily used because of its popularity in AEC professional community. However, we also use other software, including non-commercial ones. In future studies we will explore their applicability and compare where it is more convenient to solve certain problems. Open software can make the technology more open, transparent, cheap and cost-effective, increasing its popularity.

\section{ACKNOWLEDGEMENTS}

The research is carried out with the financial support of the Ministry of Science and Higher Education of Russian Federation within the framework of the Federal Program "Research and Development in Priority Areas for the Development of the Russian Science and Technology Complex for 2014-2020". The unique identifier of the project is RFMEFI58417X0025.

\section{REFERENCES}

Anil, E.B., Tang, P., Akinci, B., Huber, D. 2013. Deviation analysis method for the assessment of the quality of the as-is Building Information Models generated from point cloud data. Automation in Construction, 35, 507-516. doi.org/10.1016/j.autcon.2013.06.003

Antón, D., Medjdoub, B., Shrahily, R., Moyano, J. 2018. Accuracy evaluation of the semi-automatic 3D modeling for historical building information models. International Journal of
Architectural Heritage, 12(5), 790-805.

doi.org/10.1080/15583058.2017.1415391

Badenko, V., Fedotov, A., Vinogradov, K. 2018a. Algorithms of laser scanner data processing for ground surface reconstruction Lecture Notes in Computer Science (including subseries Lecture Notes in Artificial Intelligence and Lecture Notes in Bioinformatics), 10961 LNCS, 397-411. doi.org/10.1007/978-3-319-95165-2_28

Badenko, V., Zotov, D., Fedotov, A. 2018b. Hybrid processing of laser scanning data. E3S Web of Conferences, 33, 01047. doi.org/10.1051/e3sconf/20183301047

Badenko, V., Volgin, D., Lytkin, S. 2018c. Deformation monitoring using laser scanned point clouds and BIM. MATEC Web of Conferences. 245, 01002.

doi.org/10.1051/matecconf/201824501002

Barazzetti, L. 2016. Parametric as-built model generation of complex shapes from point clouds. Advanced Engineering Informatics, 30(3), 298-311. doi.org/10.1016/j.autcon.2014.05.014

Bosché, F., Ahmed, M., Turkan, Y., Haas, C. T., Haas, R. 2015. The value of integrating Scan-to-BIM and Scan-vs-BIM techniques for construction monitoring using laser scanning and BIM: The case of cylindrical MEP components. Automation in Construction, 49, 201-213.

doi.org/10.1016/j.autcon.2014.05.014

Brumana, R., Della Torre, S., Previtali, M., Barazzetti, L., Cantini, L., Oreni, D., Banfi, F. 2018. Generative HBIM modelling to embody complexity (LOD, LOG, LOA, LOI): surveying, preservation, site intervention - the Basilica di Collemaggio (L'Aquila). Applied Geomatics, 10(4), 545-567. doi.org/10.1007/s12518-018-0233-3

Dore, C., Murphy, M. 2017. Current state of the art historic building information modelling. International Archives of the Photogrammetry, Remote Sensing and Spatial Information Sciences - ISPRS Archives. 42(2W5), 185-192.

doi.org/10.5194/isprs-archives-XLII-2-W5-185-2017

Fateeva, E., Badenko, V., Fedotov, A., Kochetkov, I. 2018. System analysis of the quality of meshes in HBIM. MATEC Web of Conferences. 170, 03033.

doi.org/10.1051/matecconf/201817003033

Ghaffarianhoseini, A., Tookey, J., Ghaffarianhoseini, A., Naismith, N., Azhar, S., Efimova, O., Raahemifar, K. 2017. Building Information Modelling (BIM) uptake: Clear benefits, understanding its implementation, risks and challenges. Renewable and Sustainable Energy Reviews, 75, 1046-1053. doi.org/10.1016/j.rser.2016.11.083

Kivits, R. A., Furneaux, C. 2013. BIM: enabling sustainability and asset management through knowledge management. The Scientific World Journal, 2013, 983721.

doi.org/10.1155/2013/983721

Leite, F., Akinci, B. 2011. Formalized representation for supporting automated identification of critical assets in facilities during emergencies triggered by failures in building systems. Journal of Computing in Civil Engineering, 26(4), 519-529. doi.org/10.1061/(ASCE)CP.1943-5487.0000171 
Nguyen, C.H.P., Choi, Y. 2018. Comparison of point cloud data and 3D CAD data for on-site dimensional inspection of industrial plant piping systems. Automation in Construction, 91, 44-52. doi.org/10.1016/j.autcon.2018.03.008

Pärn, E.A., Edwards, D J., Sing, M.C.P. 2017. The building information modelling trajectory in facilities management: A review. Automation in Construction, 75, 45-55.

doi.org/10.1016/j.autcon.2016.12.003

Pocobelli, D. P., Boehm, J., Bryan, P., Still, J., Grau-Bové, J. 2018. Building information models for monitoring and simulation data in heritage buildings. International Archives of the Photogrammetry, Remote Sensing and Spatial Information Sciences - ISPRS Archives. 42(2), 909-916.

doi.org/10.5194/isprs-archives-XLII-2-909-2018

Roberts, C.J., Pärn, E.A., Edwards, D.J., Aigbavboa, C. 2018. Digitalising asset management: concomitant benefits and persistent challenges. International Journal of Building Pathology and Adaptation, 36(2), 152-173.

doi.org/10.1108/IJBPA-09-2017-0036

Saleeb, N., Marzouk, M., Atteya, U. 2018. A comparative suitability study between classification systems for bim in heritage. Building Information Systems in the Construction Industry, 13(1), 130-138.

doi.org/10.2495/SDP-V13-N1-130-138

Son, H., Kim, C. 2017. Semantic as-built 3D modeling of structural elements of buildings based on local concavity and convexity. Advanced Engineering Informatics, 34, 114-124.

doi.org/10.1016/j.aei.2017.10.001

Tang, P., Huber, D., Akinci, B., Lipman, R., Lytle, A. 2010. Automatic reconstruction of as-built building information models from laser-scanned point clouds: A review of related techniques. Automation in construction, 19(7), 829-843.

doi.org/10.1016/j.autcon.2010.06.007

The OmniClass Construction Classification System, 2019. http://www.omniclass.org/ (10 April 2019)

Volk, R., Stengel, J., Schultmann, F. 2014. Building Information Modeling (BIM) for existing buildings-Literature review and future needs. Automation in construction, 38, 109127. doi.org/10.1016/j.autcon.2013.10.023

Wang, Q., Guo, J., Kim, M.-K. 2019. An application oriented scan-to-bim framework. Remote Sensing, 11(3), 365. doi.org/10.3390/rs11030365

Whyte, J., Stasis, A., Lindkvist, C. 2016. Managing change in the delivery of complex projects: Configuration management, asset information and 'big data'. International Journal of Project Management, 34(2), 339-351.

doi.org/10.1016/j.ijproman.2015.02.006 